\title{
Influência dos Controles Formais e Informais e da Confiança no Comprometimento Organizacional
}

\author{
Marines Lucia Boff \\ https://orcid.org/0000-0001-8424-1095 | E-mail: marines.boff@udesc.br \\ Carline Rakowski Savariz \\ https://orcid.org/0000-0002-0062-1566 ｜ E-mail: carlinerakowski@gmail.com \\ Ilse Maria Beuren \\ https://orcid.org/0000-0003-4007-6408 | E-mail: ilse.beuren@gmail.com
}

\section{Resumo}

Objetivo: As implicações dos controles formais e informais e da confiança no comprometimento organizacional representam uma importante lacuna de pesquisa devido aos seus possíveis efeitos no desempenho dos indivíduos no trabalho. Embora estudos prévios tenham encontrado relação significante de controles formais e/ou informais com confiança e/ou comprometimento organizacional, o efeito da confiança organizacional nesta relação instiga mais pesquisas. Assim, este estudo objetiva analisar a influência dos controles formais e informais no comprometimento organizacional, mediada pela confiança organizacional. Método: Uma pesquisa de levantamento foi realizada com gestores das 150 Melhores Empresas para Trabalhar, identificados na rede social LinkedIn. Dos 746 convites enviados para participar da pesquisa, 219 foram aceitos, aos quais foi enviado o link do questionário, obtendo-se 84 respostas válidas.Os construtos foram mensurados com instrumentos validados nas pesquisas de Goebel e Weißenberger (2017) e Verburg, Nienaber, Searle, Weibel, Hartoge Rupp (2018). Para testar as hipóteses, aplicou-se a técnica de modelagem de equações estruturais.

Resultados: Os resultados da pesquisa demonstram que os controles formais e informais influenciam no comprometimento organizacional e a mediação da confiança organizacional apresenta efeito indireto nesta relação. Isso indica que a interação dos controles formais e informais com o comprometimento organizacional é reforçada pela confiança organizacional.

Contribuições: Estes resultados ampliam o escopo das análises do efeito da confiança organizacional enquanto fator que potencializa a influência dos controles formais e informais no comprometimento organizacional. Assim, o estudo contribui ao proceder a análise conjunta destes construtos com vistas nas evidências dos efeitos de controles da organização em aspectos comportamentais dos indivíduos.

Palavras-chave: Controles Formais e Informais. Confiança Organizacional.Comprometimento Organizacional. 


\section{Introdução}

Storey (1985) já alertava que a problemática das pesquisas relativas aos Sistemas de Controle Gerencial (SCG) não é como melhorar o controle, mas, sim, como servem enquanto dispositivos de controle. Nessa perspectiva, Widener (2019) observa que os estudos sobre SCGvêm examinando características de planejamento e uso e sua relação com o comportamento do funcionário. Uma das principais finalidades do controle gerencial no contexto da tomada de decisão é alinhar os comportamentos individuais aos interesses da organização (Sprinkle, 2003) por meio da interação entre controles formais e informais, os quais constituem o SCG de uma organização (Otley, 1980).

Uma das dimensões intangíveis essenciais da organização é a qualidade da coordenação e coerência do comportamento de seus membros (Guibert \& Dupuy, 1997). Tayler e Bloomfield (2011) argumentam que, apesar do uso de mecanismos de monitoramento e incentivos pelos gestores para induzir o comportamento desejado dos funcionários, os mecanismos de controle formal são limitados devido à escassez de dados que indiquem precisamente como e quando influenciarão e quais as motivações psicológicas. Nesse aspecto, Khodyakov (2007) destaca que relacionamentos de confiança tornam as pessoas menos vulneráveis quanto aos comportamentos esperados (mas não obrigatórios)de seus colegas no sentido de agir no melhor interesse da organização.

Ao analisar como os controles formais e informais estão relacionados à eficácia do SCG e ao comprometimento organizacional e como estes influenciam o desempenho organizacional, Goebel e Weißenberger (2017) constataram que os mecanismos informais de controle contribuem fortemente para maior eficácia do SCG e níveis de comprometimento organizacional que, por sua vez, levam ao desempenho organizacional superior. Estes resultados indicam maior dependência dos mecanismos de controle informal (de pessoal e cultural) do que formal (de resultado e de ação) pelas organizações contemporâneas (Goebel \& Weißenberger, 2017) e, portanto, sua importância como controles de gestão.

É nesse contexto que entender a atuação dos indivíduos nas organizações em relação aos controles formais e/ou informais é fundamental. Nesta perspectiva, conjectura-se que compreender o comprometimento organizacional dos indivíduos e sua relação com a confiança organizacional é um passo à frente nos estudos de contabilidade, pois, nas últimas décadas, a confiança tem sido enfatizada como um dos principais recursos que promovem o desempenho organizacional, visto que reflete nas atitudes dos indivíduos no trabalho dentro da organização (Baek \& Jung, 2015).

A confiança organizacional deve ser considerada nas práticas gerenciais porque pode afetar os resultados no local de trabalho (Zhang, Tsui, Song, Li \& Jia, 2008). A confiança é um construto latente formado por três dimensões: confiança entre superiores e subordinados, confiança entre colegas de trabalho e confiança organizacional (Yandra, 2017). Ressalta-se que a confiança interpessoal (entre indivíduos) difere da confiança organizacional, pois, embora um indivíduo possa entender claramente as dependências e os riscos associados ao lidar com outro indivíduo, esses riscos se tornam mais amplos e mais ambíguos no caso de uma organização (Weibel, Den Hartog, Gillespie, Searle, Six\& Skinner, 2016). Na confiança organizacional é menos nítido o que precisa ser julgado, quem é responsável pelas ações e como essas ações podem criar vulnerabilidade ao funcionário (Weibel et al., 2016).

Investigar "acerca do comportamento organizacional é importante por levar em conta a subjetividade e os comportamentos dos indivíduos dentro das organizações" (Vieira, Anjos \& Silva, 2016, p. 153). Neste aspecto, Yao, Qiu e Wei (2019) destacam que o comprometimento organizacional se desenvolve a partir de interações formais e informais entre indivíduos e organizações, o que sugere relação entre confiança e comprometimento organizacional. No entanto, Batac e Carassus (2009) alertam que novas questões surgem como a busca por uma forma de controle formalizada, mas flexível o suficiente para se ajustar às mudanças ambientais. Otley (2016)defende que a literatura atual está interessada nos efeitos que diferentes configurações de SCG exercem no comportamento dos indivíduos e organizações. 
Nessa perspectiva, estudos pregressos investigaram relações de um ou alguns elementos dos SCG com confiança organizacional (Weibel et al., 2016; Verburg et al., 2018),comprometimento organizacional(Sholihin \& Pike, 2010; Goebel e Weißenberger, 2017), confiança e comprometimento organizacional (Beuren, Klein, Lara \& Almeida, 2016). Outros estudos analisaram o efeito mediador da confiança organizacional na relação entre confiança interpessoal e comprometimento organizacional (Baek \& Jung, 2015) e na relação da troca social e econômica com o comprometimento organizacional (Ozmen, 2019), assim comoa relação entre confiança e comprometimento organizacional (Yandra, 2017). Dessa forma, as implicações dos controles formais e informais e da confiança dos funcionários com o comprometimento organizacional se apresentam como uma lacuna de pesquisa.

Embora pesquisas anteriores já tenham focado a relação de elementos dos SCG com a confiança e/ou comprometimento organizacional, ainda resta esclarecer como a confiança organizacional interfere na relação dos controles formais e informais com o comprometimento organizacional. Neste sentido, tem-se a seguinte questão de pesquisa: Qual a influência dos controles formais e informais e da confiança organizacional no comprometimento organizacional?Assim, o estudo objetiva analisar a influência dos controles formais e informais no comprometimento organizacional, mediada pela confiança organizacional. A pesquisa foi realizada com gestores das 150 Melhores Empresas para Trabalhar sob a premissa de que estas empresas possuem uma estruturada de controles formais e informais com gestores implicados em comportamentos de confiança e comprometimento.

A pesquisa em contabilidade gerencial pode ajudar a determinar em que medida os motivos sociais, os valores individuais e os controles informais das empresas interagem com procedimentos formais de gestão, ajudando a assegurar que os funcionários realizem ações no melhor interesse da organização (Sprinkle, 2003). Este estudo considera o efeito de controles formais e informais no comportamento dos funcionários. Malmi e Brown (2008) aduzem que os componentes de um SCG não funcionam isoladamente e o efeito de um deve ser considerado no contexto de outros componentes do SCG. Dado que alguns são inerentes à contabilidade e outros transversais, é relevante compreender como eles se complementam.

Este estudo contribui para a literatura aorevelar o efeito mediador da confiança organizacional na relação dos controles formais e informais com o comprometimento organizacional. Otley (2016) destaca que ao longo dos anos os pesquisadores ampliaram as variáveis dependentes e independentes analisadas no contexto dos SCG, com ênfase maior para as variáveis independentes do que dependentes. Desta forma, o presente estudo contribui para ofluxo da pesquisa que busca demonstrar como a relação entre os SCG e os resultados é explicada por variáveis intervenientes, conforme sugerido por Chenhall (2003).

Contribui também para a prática gerencial ao ter como premissa que é essencial as organizações compreenderem como a confiança e o controle se relacionam e como possíveis efeitos negativos do controle sobre a confiança podem ser evitados (Weibelet al., 2016). Conforme esses autores, os SCG são concebidos na literatura como uma forma central de influenciar o comprometimento e a confiança dos funcionários. Ao confirmar a relação dos controles formais e informais com o comprometimento organizacional, mediada pela confiança, alerta-se que as expectativas e o comportamento dos funcionários devem ser considerados no contexto do SCG, visto que podem potencializar a confiança organizacional. 


\section{Revisão da Literatura}

\subsection{Controles formais e informais e confiança organizacional}

O controle organizacional compreende a especificação de padrões para alinhar as ações dos funcionários aos objetivos da organização,de modo a influenciá-los a agir e tomar decisões que sejam consistentes com os objetivos organizacionais (Flamholtz, Das \& Tsui, 1985).Para obter controle sobre o comportamento das pessoas, as organizações usam uma combinação de mecanismos, incluindo supervisão pessoal, padrões de procedimentos operacionais, descrições de funções, mensuração do desempenho e sistemas de recompensas(Flamholtz et al., 1985). Neste sentido, SCG podem ser usados para o controle dos grupos de trabalho em todos os níveis organizacionais.

A razão de ser dos SCG é aumentar a probabilidade das pessoas internalizar os objetivos organizacionais e se comportar de modo a levá-las à consecução das metas (Flamholtz et al., 1985).De acordo com Ansari (1977, p. 102), os SCG representam"os arranjos e ações organizacionais projetados para facilitar seus membros a alcançar um desempenho mais elevado com menos consequências não intencionais".Por outro lado, Sprinkle (2003) destaca que os SCG da organização desempenham papel relevante na motivação dos funcionários e na melhoria de seus julgamentos e decisões.

Os SCG configuram práticas de controle formal e informal (Verburget al., 2018). Os controles formais incluem regras, padrões de procedimentos operacionais e sistemasque visam garantir que resultados específicos sejam alcançados e envolvem monitoramento, mensuração e ações corretivas (Langfield-Smith, 1997).Já os controles informais incluem políticas não escritas da organização e muitas vezes derivam da cultura organizacional (Langfield-Smith, 1997). Os controles informais são elementos importantes dos SCG, já que a eficácia dos controles formais pode depender da natureza dos controles informais (Otley, 1980; Flamholtz et al., 1985).

GoebeleWeißenberger (2017)destacam que os controles gerenciais visam atender diversificados objetivos organizacionais, por meio de controles formais de resultado e de ação dos funcionários, assim como por controles informais inerentes aos funcionários e à cultura organizacional. Explicam que os controles formais de resultados consistem em indicadores das metas para monitorar e avaliar o desempenho dos funcionários, enquanto os controles de ação dos funcionários visam garantir que conduzam as atividades em linha com os objetivos organizacionais e as políticas e manuais de procedimentos.Os controles informais de pessoal denotam o contexto de seleção e admissão, programas de treinamento e avaliação dos funcionários, enquanto os controles culturais compreendem normas, crenças e valores organizacionais que podem influenciar o comportamento dos funcionários.

No entanto, Guibert e Dupuy (1997) aduzem que há relação entre os dois tipos de controle gerencial, formal e informal. De acordo com esses autores, enquanto o controle formal é reconhecido como substituto do controle informal, cuja lógica substitucional sugere um constante reequilíbrio de um tipo de controle por outro, o controle informal baseia-se em um princípio de complementaridade. Conforme Batac e Carassus (2009), os instrumentos informais de gestão podem complementar em vez de substituir o controle tradicional (formal).

Se os controles formais rígidos podem prejudicar a confiança organizacional porque reduzem a autonomia dos funcionários, os controles informais, por sua vez, podem estimular relacionamentos confiáveis e, nesta perspectiva, confiança e controle se complementam (Khodyakov, 2007). Em linha, Schoorman, Mayer e Davis (2007) observam que o controle formal rigoroso pode inibir o desenvolvimento da confiança organizacional ao sinalizar que os funcionários estão apenas cumprindo com as exigências de controle em vez de agir de acordo com suas intenções dignas de confiança. 
Como a confiança organizacional se relaciona com o controle, ainda não está elucidado (Weibel et al., 2016).Hartmanne Slapnicar (2009) realizaram um estudo no qual estabeleceram e testaram um modelo de relação entre controle formal e confiança para verificar se o sistema de controle formal tem efeito sobre a confiança. Constataram que os controles formais de avaliação de desempenho influenciam na confiança interpessoal. Verburg et al. (2018) investigaram a confiança organizacional como resultado do controle gerenciale inferiram que a confiança organizacional pode ser resultado do controle gerencial, uma vez que esse pode levar à percepção de zelo organizacional e, assim, promover a confiança. Nesta perspectiva, confiança e controle produzem um ao outro (Khodyakov, 2007).Assim,apoiado nos estudos mencionados, formulou-se a primeira hipótese da pesquisa:

$\mathbf{H}_{1}$ : Os controles formais e informais têm relação positiva e significativa com a confiança organizacional.

\subsection{Confiança organizacional e comprometimento organizacional}

No ambiente organizacional, a confiança pode envolver uma variedade de atores, incluindo indivíduos (confiança em um supervisor ou colega), grupos específicos (gestores, colegas de trabalho, equipe/grupo de trabalho) ou a organização como um todo (Schoorman, Mayer \& Davis, 2007). A confiança organizacional é instituída entre os indivíduos e a organização ou as unidades organizacionais em que trabalham (Baek\& Jung, 2015). A confiança organizacional é representada pelo coletivo, ao invés de uma única pessoa, o que a difere da confiança interpessoal (Weibel et al., 2016).

Seconfiança organizacional significa ter expectativas positivas sobre a organização (Tan \& Tan, 2000), é importante considerar a influência da confiança em medidas comportamentais (Baek\& Jung, 2015).A confiança advém das avaliações dos funcionários sobre se a organização tem competência para cumprir metas e responsabilidades de forma confiável (capacidade organizacional), sinaliza intenções positivas quanto ao bem-estar das partes interessadas (benevolência organizacional) e adere aos princípios morais geralmente aceitos (integridade organizacional) em suas relações com diferentes stakeholders (Gillespie\&Dietz, 2009; Searle, Den Hartog, Weibel, Gillespie, Six,Hatzakis\& Skinner, 2011).

A confiança é de importância crítica para as organizações (Verburget al., 2018). Se torna especialmente importante quando os membros da organização estão em condições de trabalho que requerem colaboração (Coletti, Sedatole\&Towry, 2005). Elaintensifica o compartilhamento de conhecimento entre os funcionários, além de favorecer sua cooperação e comprometimento com a organização (Dirks\&Ferrin, 2001; Fulmer\&Gelfand, 2012). Os funcionários que confiam são mais comprometidos e permanecem na organização por mais tempo, trabalham mais e de forma mais cooperativa, compartilham conhecimentos e solucionam problemas com maior eficácia (Weibelet al.,2016).

Desta maneira, as organizações buscamassegurar que as operações sejam executadas sem problemas, as metas sejam alcançadas com eficiência e os funcionários cooperam com os gerentes e uns com os outros (Khodyakov, 2007). No entanto, "a organização pode vir a facilitar ou dificultar o processo de desenvolvimento do comprometimento" (Arraes, Cabral, Santos, Silva\& Penha, 2017, p. 69).O estudo de Yandra (2017) fornece evidências de que a confiança está positivamente relacionada com o comprometimento organizacional. Como consequência, a confiança organizacional é um meio pelo qual as práticas gerenciais podem afetar os resultados no local de trabalho (Zhanget al., 2008). 
Lau e Sholihin (2005) encontraram relação positiva e significativa entre confiança organizacional e satisfação no trabalho, mas não entre confiança e comprometimento organizacional. No estudo de Sholihin e Pike (2010), em uma pesquisa semelhante, mas com diferente objeto de investigação, os resultados divergiram, pois encontraram relação positiva e significativa entre confiança e comprometimento organizacional, mas não encontraram relação significativa entre confiança organizacional e satisfação no trabalho. Pranitasari (2020) observou efeito positivo da confiança organizacional no comprometimento organizacional e na motivação no trabalho. Apesar de algumas incongruências, os resultados destes estudos levaram à formulação da segunda hipótese da pesquisa:

$\mathbf{H}_{2}$ : A confiança organizacional tem relação positiva e significativa com o comprometimento organizacional.

\subsection{Controles formais e informais, confiança e comprometimento organizacional}

Chenhall (2003), a partir de uma revisão sistemática da literatura sobre SCG, sugere que estudos podem identificar antecedentes ou demonstrar como a relação entre o SCG e os resultados é explicada por variáveis intervenientes. Neste debate teórico tornou-se relevante e estimulante a pesquisa sobre as relações entre controle e confiança nas organizações (Khodyakov, 2007; Weibel et al., 2016; Verburget al., 2018), uma vez que medidas incompletas de controle (ex.: incentivos e desempenho) podem motivar comportamentos disfuncionais (Widener, 2019). A premissa é que o grau de confiança dos funcionários na organização tem potencial de influenciar nas suas atitudes (Baek \& Jung, 2015).

A preocupação com os atributos individuais pode ser combinada com o contexto organizacional, examinando a compatibilidade entre os indivíduos e sua situação de trabalho (Chenhall, 2003). Um ambiente de trabalho harmonioso aumentará o volume de troca de informações entre os indivíduos dentro da organização, criará comunicação e colaboração e ajudará uns aos outros nas dificuldades encontradas em cada atividade (Yandra, 2017). Assim, parece provável que a personalidade, o estilo cognitivo e as questões associadas ao comprometimento e à confiança acabam por ajudar a explicar como os indivíduos reagem às informações (Chenhall, 2003).

Embora não se tenha identificado na literatura estudos prévios sobre o efeito mediador da confiança na relação dos controles formais e informais com o comprometimento organizacional, há indícios que sugerem relação positiva. O estudo de Hartmann e Slapnicar (2009) constatou que os controles formais de avaliação de desempenho influenciam na confiança interpessoal, especialmente pelo fato de melhorar a qualidade percebida do feedback para os subordinados. Verburg et al. (2018) observaram que a capacidade dos controles gerenciais melhora o desempenho dos funcionários tanto diretamente quanto indiretamente pela mediação da confiança organizacional, o que indica que a relação entre controle e confiança é sensível à maneira como o comportamento é controlado.

O comprometimento organizacional deve ser visto como um relacionamento em que funcionários tendem a dar algo para contribuir com a organização (Oliveira \&Rowe, 2018).Yandra (2017) aduz que a lealdade à organização é reflexo do comprometimento organizacional decada indivíduo. Funcionários que se identificam com sua organização e apresentam altos níveis de comprometimento são mais propensos a contribuir para os objetivos organizacionais (Davis, Schoorman\&Donaldson, 1997; Hernandez, 2008), e podem promover desempenho organizacional superior (Goebel\&Weißenberger, 2017). Yao, et al. (2019) verificaram que o comprometimento organizacional se desenvolve a partir das interações formais e informais entre indivíduos e organizações, o que sugere uma relação de confiança e comprometimento organizacional. Ozmen (2019) constatou que as relações de troca social e econômica com comprometimento organizacional são mediadas pela confiança. 
Dado que os resultados de pesquisas pregressas sugerem influência positiva dos controles formais e informais na confiança organizacional (Weibel et al., 2016; Verburg et al., 2018) e da confiança organizacional no comprometimento organizacional (Sholihinj\&Pike, 2010;Baek\& Jung, 2015; Yandra, 2017; Ozmen, 2019), mesmo que algumas pesquisas não tenham encontrado relação entre confiança organizacional e comprometimento organizacional (Lau\&Sholihin, 2005), neste estudo presumese efeito mediador da confiança organizacional na relação dos controles formais e informais com o comprometimento organizacional. A partir disso, formulou-se a terceira hipótese da pesquisa:

$\mathbf{H}_{3}$ : Os controles formais e informais têm relação positiva e significativa como comprometimento organizacional, cuja relação é mediada pela confiança organizacional.

Na Figura 1, apresenta-se o modelo teórico da pesquisa, em que se destaca a relação causal entre os construtos (independente/ dependente) e as hipóteses.

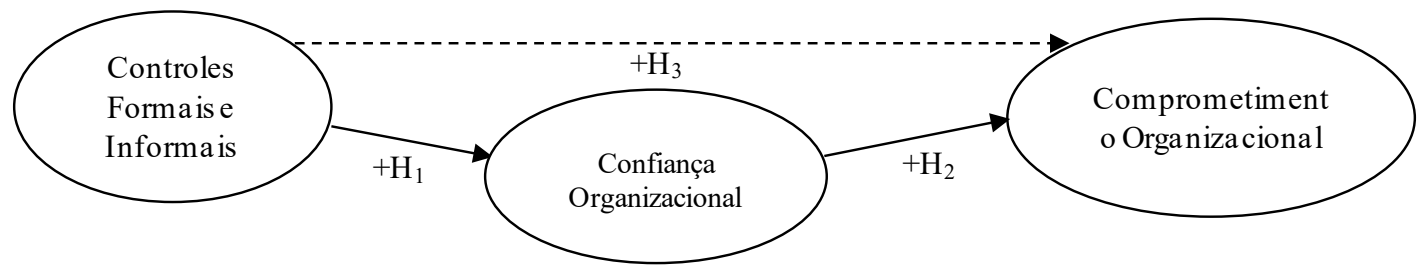

Figura 1. Modelo teórico da pesquisa

Fonte: elaboração própria.

A Figura 1 representa o modelo teórico da pesquisa, em que os controles formais e informais se relacionam positivamente com a confiança organizacional e, esta, com o comprometimento organizacional. O modelo prevê ainda que a confiança medeia a relação entre os controles formais e informais e o comprometimento organizacional.Resultados de estudos anteriores mostram que, em geral, as organizações dependem de uma variedade e diferentes mecanismos de controle que, por sua vez, devem ser analisados simultaneamente para examinar seus respectivos efeitos distintos e relativos (Goebe l\& Weißenberger, 2017).

\section{Metodologia}

Esta pesquisa foi realizada por meio de um levantamento com os 150 Melhores Empresas para Trabalhar, ranking de 2018, identificados na rede social LinkedIn. Optou-se por esta população pelo fato de os funcionários avaliarem as empresas que se inscrevem voluntariamente para participar do ranking anual. Assim, presume-se que empresas destacadas na gestão de pessoas e que na percepção dos funcionários apresentam um bom ambiente organizacional tendem a obter confiança e comprometimento organizacional.

Na rede social LinkedIn, inicialmente pesquisou-se o nome da empresa e, ao localizá-la, buscou-se visualizar todos os funcionários da empresa, tendo como filtro o 'Idioma do Perfil' eo 'Cargo,delimitandoos para'Português' e 'Gerente', respectivamente. Na ausência de funcionários na função de gerente, limitado a no máximo cinco pessoas por empresa, selecionaram-se os funcionários com cargos declarados de analistas, controllers, responsável pela controladoria, gestor e supervisor. A seleção de funcionários com cargos de gestão decorre da presunção deque possuem conhecimento suficiente para responder às questões relativas ao SCG da empresa. 
Após a identificação dos funcionários com cargos de gestão, o passo seguinte foi lhes enviar um convite para fazer parte da rede social LinkedIn criada para esta pesquisa. Dos 746 convites enviados, 484 aceitaram fazer parte da rede e, conforme os convites eram aceitos, consultava-se sobre a disponibilidade de participar da pesquisa. Aos 219 que aceitaram participar foi encaminhado o link do questionário, disponibilizado na plataforma Google Forms no período de fevereiro a abril de 2019, assegurando-lhes anonimato das respostas. A amostra final compõe-se das 84 respostas válidas, superior ao tamanho mínimo de 68 respostas calculado pelo $G^{\star}$ Power conforme recomendações de Ringle, Silva e Bido (2014).

Para mensurar os construtos da pesquisa, utilizaram-se instrumentos de pesquisa já validados em pesquisas anteriores, conforme demonstrado na Tabela 1.

Tabela 1

Construtos da pesquisa

\begin{tabular}{|c|c|c|c|}
\hline \multicolumn{2}{|c|}{ Construtos } & Descrição & Autores \\
\hline \multirow[b]{2}{*}{ Controles } & Formais & $\begin{array}{l}\text { São controles formalizados e baseados em } \\
\text { padrões explícitos e quantificáveis. }\end{array}$ & Goebel e Weißenberger (2017) \\
\hline & Informais & $\begin{array}{l}\text { São controles que não estão explícitos ou } \\
\text { formalizados e que, indiretamente, fazem parte } \\
\text { dos controles da empresa. }\end{array}$ & Goebel e Weißenberger (2017) \\
\hline \multicolumn{2}{|c|}{ Confiança organizacional } & $\begin{array}{l}\text { Refere-se à percepção dos funcionários se } \\
\text { sua organização é confiável em relação à sua } \\
\text { competência e boa vontade. }\end{array}$ & Verburg et al. (2018) \\
\hline \multicolumn{2}{|c|}{$\begin{array}{l}\text { Comprometimento } \\
\text { organizacional }\end{array}$} & $\begin{array}{l}\text { Refere-se ao comprometimento e identificação dos } \\
\text { funcionários com a empresa. }\end{array}$ & Goebel e Weißenberger (2017) \\
\hline
\end{tabular}

Fonte: elaboração própria.

Em vista do objetivo deste estudo, nem todos os construtos da pesquisa de Goebel e Weißenberger (2017) foram considerados, tais como: eficácia dos SCG e desempenho organizacional. Da pesquisa de Verburg et al. (2018) alguns construtos também não foram considerados, são eles: controles de resultado, controles normativos, controles de desempenho e controles de comportamento.De Goebel e Weißenberger (2017) utilizaram-se todos os itens das variáveis controles formais (controles de resultados, cinco itens; e controles de ação, cinco itens), controles informais (controles de pessoal, cinco itens; e controles culturais, seis itens) e comprometimento organizacional (com cinco itens). DeVerburg et al. (2018), para mensurar a confiança organizacional utilizou-se o instrumento de pesquisa com 10 itens.

Esses instrumentos de pesquisa foram traduzidos do idioma Inglês para o Português e, após isso,fezse uma tradução reversa para garantir o máximo da fidelidade aos itens originais. Sem perder seu propósito e capacidade de mensuração, a redação (rotulação das escalas) e o número de pontos das escalas dos estudos base foram ligeiramente ajustadas. Assim, o instrumento da pesquisa compõe-se de 36 assertivas com escala Likert de cinco pontos (Apêndice A), de modo ao respondente assinalar a escala de maior conformidade com a realidade da organização. No final do instrumento de pesquisa, incluíram-se quatro questões para caracterização dos participantes da pesquisa.

De acordo com Curado, Teles e Marôco (2014), a discussão sobre o número de pontos das escalas dos questionários, se par ou ímpar, é irrelevante, contudo, sugerem que quando da procura ou construção de um instrumento, deve-se priorizar medidas que tenham pelo menos cinco pontos, visto que aumenta a possibilidade de respostas dos participantes e melhora a qualidade da soma dos itens. Ao avaliar a facilidade, velocidade e precisão de escalas distintas, Dalmoro e Vieira (2013) observaram que a escala de cinco pontos é a mais adequada, uma vez que apresenta a mesma precisão de resposta que a de três pontos, mas é mais fácil e mais rápida de processar que a escala de sete pontos. 
Os dados coletados foram submetidos à análise de estatística descritiva e modelagem de equações estruturais (SEM) estimada pelo ajuste de mínimos quadrados parciais (Partial Least Square - PLS),com o uso do software Smart PLS. O PLS-SEM ultrapassa as limitações técnicas de outras estatísticas tradicionais, visto que, conforme Ringle et al. (2014, p. 57), com esta técnica "consegue-se estimar modelos mais complexos com número menor de dados", com várias relações (HairJr., Hult, Ringle \& Sarstedt, 2014), como é o caso da presente pesquisa. Assim como no estudo de Goebel e Weißenberger (2017) e Verburg et al. (2018), na abordagem PLS a base de variância foi associada com várias características distintivas que suportaram este estudo.

\section{Análise dos resultados}

Nesta seção são apresentados os resultados dos procedimentos estatísticos. Inicia-se com a descrição do perfil dos respondentes. Segue-se com a validação do modelo estrutural e o modelo de mensuração, além da discussão dos resultados deste estudo. Ressalta-se que o algoritmo PLS tem por princípio o cálculo simultâneo de vários modelos de mensuração, isto é, as relações entre indicadores e as respectivas construções latentes, além do modelo estrutural que quantifica a relação entre estas variáveis (Ringle et al., 2014).

$\mathrm{Na}$ Tabela 2, apresentam-se as características dos respondentes da pesquisa, em que se destaca o gênero, tempo no cargo, escolaridade e área de formação.

Tabela 2

Caracterização dos respondentes

\begin{tabular}{lcclcr}
\hline \multicolumn{1}{c}{ Gênero } & Frequência & $\boldsymbol{\%}$ & Escolaridade & Frequência & \% \\
\hline Feminino & 21 & $25 \%$ & Graduação & 23 & $27 \%$ \\
\hline Masculino & 63 & $75 \%$ & Pós-graduação & 61 & $73 \%$ \\
\hline \multicolumn{1}{c}{ Tempo no cargo } & Frequência & $\mathbf{\%}$ & Administração & $\mathbf{2 2}$ & $\mathbf{2 6 \%}$ \\
\hline 0 a 5 anos & 52 & $61 \%$ & Engenharias & 12 & $14 \%$ \\
\hline 6 a 10 anos & 15 & $18 \%$ & Contabilidade & 11 & $13 \%$ \\
\hline 11 a 20 anos & 15 & $18 \%$ & Informática/TI & 7 & $8 \%$ \\
\hline Mais de 20 anos & 2 & $3 \%$ & Comunicação Social & 11 & $13 \%$ \\
\hline & & Outras & 21 & $26 \%$ \\
\hline
\end{tabular}

Nota: $\mathrm{N}=84$.

Fonte: dados de pesquisa.

Na Tabela 2, observa-se que 75\% dos respondentes são do gênero masculino. A maior parte dos respondentes atua no cargo há cinco anos ou menos (61\%). Quanto à formação acadêmica, a maioria possui curso de pós-graduação. Verifica-se heterogeneidade na graduação dos respondentes, com predomínio do curso de Administração. Este perfil sugere adequação para responder ao instrumento de pesquisa, principalmente pelo fato de mais de um terço dos respondentes atuarem em cargos de gestão acima de cinco anos e grande parte da amostra possuir formação na área de negócios. 


\subsection{Modelo de mensuração}

A modelagem contou com uma variável de segunda ordem (controles formais e informais), que se compõe de quatro variáveis de primeiraordem (controles de resultado, controles de ação, controles pessoais e controles culturais), cuja operacionalização ocorreu pela abordagem de repetição de indicadores (Bido\& Silva, 2019). Na Tabela 3, apresentam-se os critérios para avaliar a validade convergente, discriminante e consistência interna dos construtos latentes de primeira e segunda-ordem. Ressalta-se que a Variância Média Extraída (AVE) e a Confiabilidade Composta (CR) do construto de segundaordem foram calculadas à parte, conforme explicado em Bido e Silva (2019). Para ajuste do modelo, o segundo item dos controles culturais foi excluído.

Tabela 3

Indicadores de confiabilidade e validade do modelo

\begin{tabular}{|c|c|c|c|c|c|c|c|}
\hline & Construtos & AVE & CR & AC & 1 & 2 & 3 \\
\hline \multicolumn{8}{|c|}{ Painel A - VL de primeira ordem } \\
\hline \multirow{2}{*}{$\mathrm{CF}$} & 1. Controles de Resultado & 0,575 & 0,871 & 0,815 & & & \\
\hline & 2. Controles de Ação & 0,692 & 0,918 & 0,886 & 0,741 & & \\
\hline \multirow{2}{*}{$\mathrm{Cl}$} & 3. Controles Pessoais & 0,744 & 0,936 & 0,914 & 0,707 & 0,708 & \\
\hline & 4. Controles Culturais & 0,715 & 0,926 & 0,900 & 0,711 & 0,694 & 0,796 \\
\hline \multicolumn{8}{|c|}{ Painel B - VL do modelo estrutural } \\
\hline COR & 1. Confiança organizacional & 0,663 & 0,851 & 0,942 & & & \\
\hline CORG & 2. Comprometimento organizacional & 0,666 & 0,909 & 0,874 & 0,881 & & \\
\hline CFI & 3. Controles formais e informais & 0,735 & 0,917 & 0,946 & 0,893 & 0,833 & \\
\hline
\end{tabular}

Nota: VL = Variável latente; $\mathrm{AVE}=$ Variância Média Extraída; $\mathrm{CR}=$ Confiabilidade Composta; $\mathrm{AC}=$ Alfa de Cronbach; $\mathrm{CF}=$ Controles Formais; $\mathrm{Cl}$ = Controles Informais; $\mathrm{COR}$ = Confiança Organizacional; $\mathrm{CORG}$ = Comprometimento Organizacional; $\mathrm{CFI}=$ Controles Formais e Informais.

Fonte: dados da pesquisa.

Coerente com a análise fatorial confirmatória, os itens apresentaram cargas fatoriais acima de $0,60 \mathrm{em}$ seus respectivos construtos, o que demonstra adequação (Hair Jr., 2014). Na consistência interna, assumese a validade por meio do alfa de Cronbach (AC) e CR, ambos com índices acima de 0,70 (Hair Jr., Risher, Sarstedt \& Ringle, 2019). A validade convergente foi evidenciada pela AVE com valores acima de 0,50. A validade discriminante foi comprovada pelo critério de heterotrait-monotrait ratio of correlations (HTMT), nas três últimas colunas da Tabela 3, em que os índices são menores que 0,90 (Hair Jr. et al., 2019).

\subsection{Modelo estrutural}

Após a avaliação do modelo de mensuração e a validaçãodos construtos, procedeu-se àanálise dos ajustes do modelo estrutural e a análise das hipóteses do estudo.O primeiro passo foi avaliar as validades convergentes e, para tanto,empregou-se a técnica Bootstrapping com 5.000 interações, utilizada para estimar a significância (p-valor)das relações entre as variáveis e seus respectivos construtos(Preacher\& Hayes, 2008; Ringle et al., 2014).Ou seja, quanto que cada construto influencia o construto correspondente (Hair Jr. et al., 2014). Na Tabela 4, avaliam-se as relações e respectivas hipóteses. 
Tabela 4

Análise do modelo estrutural e hipóteses

\begin{tabular}{|c|c|c|c|c|}
\hline Relações & Hipótese & Coef. & t-value & p-value \\
\hline Controles formais e informais $\rightarrow$ Confiança organizacional. & $\mathrm{H}^{1}$ & 0,855 & 25,932 & $0,000 *$ \\
\hline Confiança organizacional $\rightarrow$ Comprometimento organizacional. & $\mathrm{H}^{2}$ & 0,590 & 5,120 & $0,000 *$ \\
\hline Controles formais e informais $\rightarrow$ Comprometimento organizacional. & & 0,262 & 2,208 & $0,027 * *$ \\
\hline $\begin{array}{l}\text { Controles formais e informais } \rightarrow \text { Confiança organizacional } \rightarrow \\
\text { Comprometimento organizacional. }\end{array}$ & $\mathrm{H}^{3}$ & 0,505 & 5,013 & $0,000 *$ \\
\hline
\end{tabular}

Nota: ${ }^{*} \mathrm{p}<0,05 ;{ }^{*} \mathrm{p}<0,01$.

$R^{2}=$ Confiança organizacional $(0,729)$; Comprometimento organizacional $(0,674)$.

$Q^{2}=$ Confiança organizacional $(0,468)$; Comprometimento organizacional $(0,434)$.

Fonte: dados da pesquisa.

Buscou-se confirmar relevância preditiva e acurácia do modelo estrutural pelos coeficientes de e , respectivamente. Se os valores de forem maiores que zero, para um determinado construto, indicam relevância preditiva do modelo para este construto (Hair Jr. et al., 2014). Quanto mais próximo de $1(=1)$, melhor o modelo reflete a realidade (Ringle et al., 2014). Os valores de indicam que o modelo tem poder preditivo, uma vez que seus valores são maiores que zero.

Denota-se que os controles formais e informais (CFI) atuam positiva e significativamente sobre a confiança organizacional $(\mathrm{COR})\left(\mathrm{H}_{1}\right.$, coef. $\left.=0,855, \mathrm{p}<0,01\right)$; a confiança organizacional (COR) atua positiva e significativamente sobre o comprometimento organizacional (CORG) $\left(\mathrm{H}_{2}\right.$, coef. $=0,590$, $\mathrm{p}<0,01$ ). Em relação à $\mathrm{H}_{3}$, percebe-se que existe efeito direto dos controles formais e informais (CFI) no comprometimento organizacional $(\mathrm{CORG})(\mathrm{coef} .=0,262, \mathrm{p} \leq 0,05)$, além de efeito indireto, por meio da confiança organizacional (coef. $=0,505, p<0,01$ ). Uma vez que o efeito direto e o efeito indireto são significantes, assume-se que existe uma mediação parcial (Bido\& Silva, 2019). Contudo, cabe salientar que a relação em questão é fortalecida quando mediada pela confiança organizacional, passando de um coeficiente beta de 0,262 para 0,505.

\subsection{Discussão dos resultados}

Os resultados da pesquisa mostram que a hipótese $\mathrm{H}_{1}$, a qual prevê que os controles formais e informais têm relação positiva e significativa com a confiança organizacional, apresenta sustentação para não ser rejeitada. Esses resultados corroboram com os de Hartmann e Slapnicar (2009), de que a confiança pode ser alcançada por meio dos controles gerenciais, mas que a ligação entre ambos (controles e confiança) é sensível e está atrelada à maneira como o comportamento é controlado.Coadunam também com os resultados do estudo de Weibel et al. (2016), de que os controles se relacionam positivamente com a confiança organizacional, sendo que a relação entre controles e confiança organizacional é diferenciada quando a qualidade da implementação dos controles é considerada, enquanto controles mal implementados podem minar a confiança.

De acordo com Sprinkle (2003), os controles gerenciais têm papel fundamental na motivação dos funcionários e na melhoria dos seus julgamentos e decisões. $\mathrm{O}$ autor argumenta que,devido ao fato de as organizações possuírem uma diversidade de indivíduos, o bem-estar está indissociavelmente ligado aos julgamentos.Embora restrito ao âmbito dos indivíduos, mas na mesma direção, Hartmann e Slapnicar (2009) encontraram em seu estudo que a confiança interpessoal proporciona um ambiente de trabalho favorável.No presente estudo, a percepção dos gestores coaduna-se quanto aos efeitos dos controles formais e informais na obtenção de confiança organizacional dos funcionários. 
A hipótese $\mathrm{H}_{2}$,a qual prevê quea confiança organizacional tem relação positiva e significativa com o comprometimento organizacional, encontra sustentação para não ser rejeitada. Esses resultados corroboram com os de Ozmen (2019) e de Pranitasari (2020), que encontraram efeito positivo da confiança organizacional no comprometimento organizacional. Os resultados também confirmam o observado no estudo de Yao et al. (2019),de que a construção de uma base sólida de confiança mútua entre funcionários e empregadores é eficaz para manter a satisfação dos funcionários, desenvolver um senso de apego, pertencimento, moralidade e responsabilidade com a organização.Conforme os autores, para haver confiança e comprometimento, as empresas devem respeitar e cuidar de seus funcionários e estabelecer um senso de pertencimento mútuo.

Os resultados também corroboram com Yandra (2017) sobre a importância do papel da confiança como elemento de controle informal, que explica a relação positiva entre o controle e o comportamento dos membros de uma organização. Expectativas positivas advindas da confiança estimulam o surgimento de comportamentos positivos individuais, de modo que intensifica o comprometimento individual. DirksFerrin (2001) e Verburg et al. (2018) ressaltam que a confiança é de importância crítica para as organizações, já que intensifica o compartilhamento de conhecimento entre os funcionários, além de sua cooperação e comprometimento com a organização.

Zhang et al. (2008) observaram em sua pesquisa que ambientes de confiança podem afetar os controles gerenciais. Decorre que os controles contribuem para afirmar a reputação da empresa junto às partes interessadas, com isso afetam a confiança no funcionário. Isso sugere que um ambiente organizacional que proporciona maior confiança é determinante na satisfação e no comprometimento no trabalho. Weibel et al. (2016) destacam que a confiança na empresa reflete em maior comprometimento dos funcionários,levando a maior tempo de permanência em seu trabalho, o que contribui para o desempenho da empresa. Portanto, os resultados da hipótese $\mathrm{H}_{2}$ coadunam com a literatura elencada.

Por fim, a hipótese $\mathrm{H}_{3}$, a qual prevê que os controles formais e informais têm relação positiva e significativa com comprometimento organizacional, cuja relação é mediada pela confiança organizacional, possui sustentação para não ser rejeitada. Esses resultados alinham-seem parte com um estudo de Baek e Jung (2015),que analisou o efeito mediador da confiança organizacional na relação entre a confiança interpessoal e o comprometimento organizacional.Encontraram que a confiança interpessoal promove o comprometimento organizacional apenas se mediada pela confiança organizacional.

Goebel e Weißenberger (2017) constataram que os diferentes mecanismos de controle, formais e informais,relacionam-se com o comprometimento organizacional, com destaque para os controles informais de ação e de resultado, com relação positiva e significativa.Conforme os autores, a consideração conjunta de mecanismos formais e informais de controle fornece evidências de que os elementos dos SCG são importantes para promover o comportamento desejado dos funcionários e a criação de valor sustentável.

SholihinePike (2010) reiteram o papel significativo do comprometimento organizacional na eficácia dos SCG. Gualinga e Lennartsson (2020) ressaltam que os SCG apresentam dependência de fatores internos, como do comprometimento.Davis et al. (1997) e Hernandez (2008)observaram que funcionários que se identificam fortemente com a organização e apresentam altos níveis de comprometimento são mais propensos a contribuir para os objetivos organizacionais. Os achados do presente estudo revelaram que o uso de diferentes medidas de desempenho, financeiras e não financeiras, geram diferentes efeitos comportamentais, no caso confiança e comprometimento organizacional.

A literatura chama a atenção para trade-offs entre mecanismos formais de controle, inclinados à orientação de incentivos, e mecanismos informais de controle, como meios de identificar cultura, honestidade e confiança (Yandra, 2017). Assim, a confiança se torna importante quando os membros da organização estão em situações e condições de trabalho que requerem colaboração (Coletti et al.,2005), sinalizando que a noção de confiança parece encontrar equilíbrio entre o controle formal e o controle informal (Guibert\&Dupuy, 1997). 
Indícios são encontrados na literatura deque os controles formais e informais atuam sobre o comprometimento dos funcionários. Os resultados da presente pesquisa corroboram com a literatura, uma vez que evidenciam efeito positivo entre esses construtos e também pela mediação da confiança organizacional. Portanto, nas150 Melhores Empresas para Trabalhar pesquisadas, na percepção dos gestores respondentes da pesquisa há satisfação no trabalho e, conforme as relações positivas e significativas observadas, os controles gerenciais adotados são eficientes para impactar positivamente no comprometimento organizacional, já que também esses funcionários confiam na empresa que trabalham.

\section{Considerações Finais}

Neste estudo analisou-se a influência dos controles formais e informais no comprometimento organizacional, mediada pela confiança organizacional. Os resultados apontam que os controles formais e informais atuam positiva e significativamente sobre a confiança organizacional e quea confiança organizacional atua positiva e significativamente sobre o comprometimento organizacional. Isso sugere que é desta forma que ocorrem as interaçõesdos controles formais e informais com a confiança organizacional e desta com o comprometimento organizacional nas 150 Melhores Empresas para Trabalhar investigadas, conforme a percepção dos gestores respondentes da pesquisa.

Os resultados revelaram ainda efeito mediador da confiança organizacional na relação dos controles formais e informais com o comprometimento organizacional. Isso sugere que a confiança desenvolvida pelos funcionários leva ao comprometimento organizacional, o que conforme Weibel et al. (2016) os faz permanecerem na organização por mais tempo, trabalhar mais e de forma cooperativa, compartilhar conhecimentos e solucionar problemas com maior eficácia.Neste aspecto, os respondentes da pesquisa reportaram percepções convergentes no contexto das empresas em que trabalham, visto que todas as hipóteses foram confirmadas.

Desta maneira, os resultados da pesquisa contribuem com a literatura pregressa ao reforçar a existência de relação positiva entre controles gerenciais e confiança organizacional (Khodyakov, 2007; Hartmann \&Slapnicar, 2009; Weibel et al., 2016; Verburg et al., 2018), e relação positiva entre confiança e comprometimento organizacional (Sholihin\&Pike, 2010; Baek\& Jung, 2015; Goebel\&Weißenberger, 2017; Yandra, 2017; Yao et al., 2019). No entanto, contribui especialmente ao revelar que a confiança organizacional medeia a relação dos controles formais e informais com o comprometimento organizacional. Esse achado pode ser uma possível explicação para os resultados não congruentes de estudos anteriores.

Os resultados também contribuem para a prática gerencial, uma vez que as empresas, entendendo que a confiança do funcionário na organização potencializa a eficácia dos controles formais e informais no comprometimento organizacional, podem adotar práticas que intensificam a confiança e o comprometimento organizacional dos funcionários. Desse modo, os gestores conseguem obter desempenho superior no trabalho dos funcionários e, assim, melhorar o desempenho da organização.É possível que esse seja o cenário das empresas melhores para trabalhar, uma vez que as relações das variáveis propostas apresentaram-se positivas e significativas. Indícios podem ser observados nas características da amostra investigadas, em que a maioria está há mais de cinco anos na empresa, o que pode ser reflexo dos controles gerenciais, comprometimento e confiança, conforme apontado pela literatura. 
As limitações desta pesquisa instigam realizar novos estudos.Algumas variáveis do estudo de Goebel e Weißenberger (2017) não foram consideradas, como eficácia dos SCG, e de Verburg et al. (2018), como controles normativos. Também não foi testada a direção da causalidade dos construtos,portanto, pesquisas futuras podeminvestigarseos controles formais e informais representam antecedentes e/ou consequentes da confiança organizacional, conforme sugerido por Verburg et al. (2018), além da relação bidirecional entre confiança e desempenho organizacional, em linha com o estudo de Xu, Fernando e Tam (2019).Há ainda a possibilidade de explorar o efeito mediador de outros elementos, como traços de personalidade, na relação dos controles formais e informais com o comprometimento organizacional. Ressalta-se que a amostra deste estudo compreendeu somente funcionários em cargos de gestão, por se presumir terem conhecimento sobre o SCG da empresa, o que instiga investigar a percepção dos funcionários de apoio à gestão.

\section{Referências}

Ansari, S. L. (1977). An integrated approach to control system design. Accounting, Organizations and Society, 2(2), 101-112. https://doi.org/10.1016/0361-3682(77)90027-7

Arraes, V. M., Cabral, A. C. A., Santos, S. M., Silva, M. N. M., \& Penha, E. D. S. (2017). Relação entre aspectos de modernidade organizacional e comprometimento organizacional. Revista de Administração FACES Journal, 16(1), 66-85. https://doi.org/10.21714/1984-6975FACES2017V16N1 ART3759

Baek, Y. M., \& Jung, C. S. (2015). Focusing the mediating role of institutional trust: How does interpersonal trust promote organizational commitment? The Social Science Journal, 52(4), 481-489. https://doi. org/10.1016/j.soscij.2014.10.005

Batac, J., \&Carassus, D. (2009). Interactions between control and organizational learning in the case of a municipality: A comparative study with Kloot (1997). Management Accounting Research, 20(2), 102-116. https://doi.org/10.1016/j.mar.2008.11.001

Bido, D. S., \& Silva, D. (2019). SmartPLS 3: Especificação, estimação, avaliação e relato. Administração: Ensino e Pesquisa, 20(2), 1-31. https://doi.org/10.13058/raep.2019.v20n2.1545

Beuren, I.M., Klein, L., Lara, F.L., \& Almeida, L.B. (2016). Percepção de justiça nos sistemas de controle gerencial aumenta comprometimento e confiança dos gestores? Revista de Administração Contemporânea, 20(2), 216-237. https://doi.org/10.1590/1982-7849rac2016140083

Chenhall, R. H. (2003). Management control systems design within its organizational context: findings from contingency-based research and directions for the future. Accounting, Organizations and Society, 28(2-3), 127-168. https://doi.org/10.1016/S0361-3682(01)00027-7

Coletti, A. L., Sedatole, K. L., \&Towry, K. L. (2005). The effect of control systems on trust and cooperation in collaborative environments. The Accounting Review, 80(2), 477-500. https://doi.org/10.2308/ accr.2005.80.2.477

Curado, M. A. S., Teles, J., \&Marôco, J. (2014). Análise de variáveis não diretamente observáveis: Influência na tomada de decisão durante o processo de investigação. Revista da Escola de Enfermagem da USP, 48(1),146-152. https://doi.org/10.1590/S0080-623420140000100019

Dalmoro, M., \& Vieira K.M. (2013). Dilemas na construção de escalas tipo Likert: O número de itens e a disposição influenciam nos resultados? Revista Gestão Organizacional, 6(3), 161-174.

Davis, J. H., Schoorman, F. D., \& Donaldson, L. (1997). Toward a stewardship theory of management. Academy of Management Review, 22(1), 20-47. https://doi.org/10.5465/amr.1997.9707180258

Dirks, K. T., \& Ferrin, D. L. (2001). The role of trust in organizational settings. Organization Science, 12(4), 450-467.https://doi.org/10.1287/orsc.12.4.450.10640 
Flamholtz, E. G., Das, T. K., \&Tsui, A. S. (1985). Toward an integrative framework of organizational control. Accounting, Organizations and Society, 10(1), 35-50.https://doi.org/10.1016/0361-3682(85)90030-3

Fulmer, C. A., \& Gelfand, M. J. (2012). At what level (and in whom) we trust: Trust across multiple organizational levels. Journal of Management, 38(4), 1167-1230.https://doi. org/10.1177/0149206312439327

Gillespie, N., \& Dietz, G. (2009). Trust repair after an organization-level failure. Academy of Management Review, 34(1), 127-145. https://doi.org/10.5465/amr.2009.35713319.

Goebel, S., \&Weißenberger, B. E. (2017). The relationship between informal controls, ethical work climates, and organizational performance. Journal of Business Ethics, 141(3), 505-528. https://doi.org/10.1007/ s10551-015-2700-7

Gualinga, E. S., \&Lennartsson, D. (2020). The relationship between personality traits, management control systems, and organizational commitment: A multifirm study. Dissertation master, Uppsala University, Uppsala, Sweden.

Guibert, N., \& Dupuy, Y. (1997). La Complémentarité entre contrôleformel et contrôleinformel: le cas de la relation client fournisseur. Association Francophone de Comptabilité - Contrôle - Audit, 3(1), 39-52.

Hair Jr., J. F., Hult, G. T. M., Ringle, C., \&Sarstedt, M. (2014). Aprimer on partial least squares structural equation modeling (PLS-SEM). London: Sage Publication.

Hair Jr., J. F., Risher, J. J., Sarstedt, M., \&Ringle, C. M. (2019). When to use and how to report the results of PLS-SEM. European Business Review, 31(1), 2-24. https://doi.org/10.1108/EBR-11-2018-0203

Hartmann, F., \&Slapnicar, S. (2009). How formal performance evaluation affects trust between superior and subordinate managers. Accounting, Organizations and Society, 34(6-7), 722-737. https://doi. org/10.1016/j.aos.2008.11.004

Hernandez, M. (2008). Promoting Stewardship Behavior in Organizations: A Leadership Model. Journal of Business Ethics, 80, 121-128.https://doi.org/10.1007/s10551-007-9440-2

Khodyakov, D. M. (2007). The complexity of trust-control relationships in creative organizations: Insights from a qualitative analysis of a conductorless orchestra. Social Forces, 86(1), 1-22. https://doi. org/10.1353/sof.2007.0100

Langfield-Smith, K. (1997). Management control systems and strategy: a critical review. Accounting, Organizations and Society, 22(2), 207-232. https://doi.org/10.1016/S0361-3682(95)00040-2

Lau, C. M., \&Sholihin, M. (2005). Financial and nonfinancial performance measures: How do they affect job satisfaction? The British Accounting Review, 37(4), 389-413. https://doi.org/10.1016/j. bar.2005.06.002

Malmi, T., \& Brown, D. A. (2008). Management control systems as a package-Opportunities, challenges and research directions. Management Accounting Research, 19(4),287-300. https://doi.org/10.1016/j. mar.2008.09.003

Oliveira, P. N., \&Rowe, D. E. O. (2018). Organizational commitment in the public sector: review and research. RevistaPensamentoContemporâneoemAdministração, 12(2), 43-54.

Otley, D. (2016). The contingency theory of management accounting and control: 1980-2014. Management Accounting Research, 31, 45-62. https://doi.org/10.1016/j.mar.2016.02.001

Otley, D. T. (1980). The contingency theory of management accounting: achievement and prognosis. Accounting, Organizations and Society, 5(4), 413-428. https://doi.org/10.1016/0361-3682(80)90040-9

Ozmen, Y.S. (2019). How the exchange relationship affects employee commitment: The mediating role of organizational trust. Journal of Management Development, 38(6), 501-516. https://doi-org.ez71. periodicos.capes.gov.br/10.1108/JMD-08-2018-0220 
Peng, D.X., \& Lai, F. (2012). Using partial least squares in operations management research: A practical guideline of past research. Journal of Operations Management, 30(6), 467-480. https://doi. org/10.1016/j.jom.2012.06.002

Pranitasari, D. (2020). The influence of effective leadership and organizational trust to teacher's work motivation and organizational commitment. Media Ekonomi dan Manajemen, 35(1), 75-91. http:// dx.doi.org/10.24856/mem.v35i1.1257

Preacher, K. J., \& Hayes, A. F. (2008). Asymptotic and resampling strategies for assessing and comparing indirect effects in multiple mediator models. Behavior Research Methods, 40(3), 879-891. https:// doi.org/10.3758/BRM.40.3.879

Ringle, C. M., Silva, D., \&Bido, D. D. S. (2014). Modelagem de equações estruturais com utilização do SmartPLS. RevistaBrasileira de Marketing, 13(2), 56-73. https://doi.org/10.5585/remark.v13i2.2717

Schoorman, F. D., Mayer, R. C., \& Davis, J. H. (2007). An integrative model of organizational trust: Past, present, and future.Academy of Management Review, 32(2), 344-354. https://doi.org/10.5465/ amr.2007.24348410

Searle, R., Den Hartog, D. N., Weibel, A., Gillespie, N., Six, F., Hatzakis, T., \& Skinner, D. (2011). Trust in the employer: The role of high-involvement work practices and procedural justice in European organizations. The International Journal of Human Resource Management, 22(5), 1069-1092. https:// doi.org/10.1080/09585192.2011.556782

Sholihin, M., \& Pike, R. (2010). Organizational commitment in the police service: exploring the effects of performance measures, procedural justice and interpersonal trust. Financial Accountability \& Management, 26(4),392-421. https://doi-org.ez71.periodicos.capes.gov.br/10.1111/j.14680408.2010.00507.x

Sprinkle, G. B. (2003). Perspectives on experimental research in managerial accounting. Accounting, Organizations and Society, 28(2-3), 287-318. https://doi.org/10.1016/S0361-3682(01)00058-7

Storey, J. (1985). The means of management control. Sociology, 19(2), 193-211. https://doi. org/10.1177/0038038585019002004

Tan, H. H., \& Tan, C. S. F. (2000). Toward the differentiation of trust in supervisor and trust in organization. Genetic, Social, and General Psychology Monographs, 126(2),241.

Tayler, W. B., \& Bloomfield, R. J. (2011). Norms, conformity, and controls. Journal of Accounting Research, 49(3),2011.https://doi.org/10.1111/j.1475-679X.2011.00398.x

Verburg, R. M., Nienaber, A. M., Searle, R. R. H., Weibel, A., Hartog, D. N. D., \&Rupp, D. E. (2018). The role of organizational control systems in employees' organizational trust and performance outcomes. Group \& Organization Management, 43(2), 179-206. https://doi.org/10.1177/1059601117725191

Vieira, J. A., Anjos, A. C., \& Silva, L. C. O. (2016). Comportamento organizacional:diferenças na produção empírica entre psicologia e administração organizacional. RevistaPensamentoContemporâneoemAdministração, 10(3), 152-162.

Weibel, A., Den Hartog, D. N., Gillespie, N., Searle, R., Six, F., \& Skinner, D. (2016). How do controls impact employee trust in the employer? Human Resource Management, 55(3),437-462. https://doiorg.ez74.periodicos.capes.gov.br/10.1002/hrm.21733

Widener, S. K. (2019). Reagrupamento dos pesquisadores para examinar a interação entre controle gerencial e ética. Revista de Contabilidade \& Finanças, 30(80), 167-171. https://doi.org/10.1590/1808057x201990300

Xu, Q., Fernando, G. D., \&Tam, K. (2019). Trust and firm performance: A bi-directional study. Advances in Accounting, 47, 100433. https://doi.org/10.1016/j.adiac.2019.100433 
Yandra, F. P. (2017). The role of trust as an informal mechanism in the management control system of performance effectiveness. The Indonesian Accounting Review, 7(1) 45-60. http://dx.doi. org/10.14414/tiar.v7i1.1218

Yao, T.,Qiu, Q, \& Wei, Y. (2019). Retaining hotel employees as internal customers: Effect of organizational commitment on attitudinal and behavioral loyalty of employees. International Journal of Hospitality Management, 76(A),1-8. https://doi.org/10.1016/j.ijhm.2018.03.018

Zhang, A. Y., Tsui, A. S., Song, L. J., Li, C., \& Jia, L. (2008). How do I trust thee? The employee-organization relationship, supervisory support, and middle manager trust in the organization. HumanResource Management, 47(1), 111-132.https://doi.org/10.1002/hrm.20200

\section{Apêndice A - Instrumento de Pesquisa}

\section{Controles Formais (Goebel\&Weißenberger, 2017, p. 212)}

\section{Controles de Resultado}

Indique em que medida as assertivas que seguem se aplicam na definição e avaliação das metas de desempenho dos funcionários da sua empresa.

Escala de 1 (Discordo totalmente) a 5 (Concordo totalmente).

1. Objetivos específicos de desempenho são estabelecidos para os funcionários.

2. A realização de metas de desempenho pelos funcionários é controlada por seus respectivos superiores.

3. Desvios potenciais das metas de desempenho devem ser explicados pelos funcionários responsáveis.

4. Os funcionários recebem feedback de seus superiores sobre em que medida atingiram suas metas de desempenho.

5. Os componentes da remuneração variável são vinculados as metas de desempenho atribuídas.

\section{Controles de Ação}

Indique em que medida as assertivas que seguem se aplicam no que concerne às políticas e manuais de procedimentos na sua empresa.

Escala de 1 (Não se aplica em absoluto) a 5 (Aplica-se completamente).

6. Superiores monitoram as medidas necessárias para atingir as metas de desempenho de seus funcionários.

7. Os superiores avaliam o modo como os funcionários realizam uma tarefa atribuída.

8. Os superiores definem as etapas de trabalho mais importantes para as tarefas rotineiras.

9. Os superiores fornecem aos funcionários informações sobre as etapas mais importantes relacionadas ao alcance das metas de desempenho.

10. Políticas e manuais de procedimentos definem o curso fundamental dos processos.

2. Controles Informais (Goebel\&Weißenberger, 2017, p. 212)

\section{Controles Pessoais}

Indique em que medida as assertivas que seguem se aplicam no que se refere aos controles específicos de seleção e admissão de funcionários na sua empresa.

Escala de 1 (Discordo totalmente) a 5 (Concordo totalmente).

11. Nossos funcionários são cuidadosamente selecionados, se eles se enquadram nos valores e normas de nossa organização.

12. Muito esforço foi feito para estabelecer o processo de recrutamento mais adequado para a nossa organização.

13. A ênfase é colocada na contratação dos candidatos mais adequados para uma posição de trabalho específica.

14. As atividades de treinamento e desenvolvimento para os funcionários são consideradas muito importantes.

15. Nossos funcionários recebem inúmeras oportunidades para ampliar sua gama de habilidades. 


\section{Controles Culturais}

Indique em que medida as assertivas que seguem se aplicam no que concerne às normas, crenças e valores compartilhados na sua empresa e que podem influenciar o comportamento dos funcionários.

Escala de 1 (Não se aplica em absoluto) a 5 (Aplica-se completamente).

16. Tradições, valores e normas desempenham um papel importante em nossa organização.

17. Em nossa organização, grande ênfase é dada ao compartilhamento de códigos informais de conduta com os funcionários.

18. Nossa declaração de missão transmite os valores fundamentais da organização para nossos funcionários.

19. Os gestores de topo comunicam os principais valores da organização aos funcionários.

20. Nossos funcionários estão cientes dos principais valores da organização.

21. Nossos funcionários percebem os valores codificados em nossa declaração de missão como motivadores.

\section{Comprometimento Organizacional (Goebel\&Weißenberger, 2017, p. 213)}

Indique em que medida as assertivas que seguem se aplicam quanto ao comprometimento e identificação dos funcionários com a sua empresa na perspectiva organizacional.

Escala de 1 (Discordo totalmente) a 5 (Concordo totalmente).

22. Nossos funcionários estão dispostos a fazer um grande esforço além do normalmente esperado para contribuir para o sucesso de nossa organização.

23. Nossos funcionários são muito leais à nossa organização.

24. Há uma elevada congruência entre os valores da nossa organização e os valores individuais de nossos funcionários.

25. O rumo da nossa organização é muito importante para nossos funcionários.

26. Nossos funcionários dizem aos amigos que nossa organização é um bom empregador.

\section{Confiança Organizacional (Verburg et al., 2018, p. 200)}

Assinale seu grau de concordância com as assertivas abaixo sobre a percepção dos funcionários se sua empresa é confiável quanto a sua competência e boa vontade.

Escala de 1 (Discordo totalmente) a 5 (Concordo totalmente).

27. A empresa é capaz de cumprir suas responsabilidades.

28. A empresa é conhecida por ser bem-sucedida no que tenta fazer.

29. A empresa faz as coisas com competência.

30. A empresa está preocupada com o bem-estar de seus funcionários.

31. As necessidades e desejos dos funcionários são importantes para a sua empresa.

32. A empresa fará de tudo para ajudar os funcionários.

33. A empresa nunca se aproveitaria deliberadamente de funcionários.

34. A empresa é guiada por sólidos princípios morais e códigos de conduta.

35. O poder não é abusado na sua empresa.

36. A empresa não explora as partes interessadas externas (fornecedores, clientes, outros). 